\title{
CULTURA ORGANIZACIONAL: APROXIMACIÓN SECTORIAL EN BOGOTÁ*
}

\author{
IGNACIO GÓMEZ ROLDÁN*** RAFAEL GUILLERMO RICARDO BRAY*** \\ FUNDACIÓN UNIVERSITARIA KONRAD LORENZ
}

Recibido/ Received/ Recebido: 05/05/2012 - Aceptado/ Accepted / Aprovado: 02/10/2012

\begin{abstract}
Resumen
Esta investigación busco identificar los perfiles de cultura organizacional en cuatro sectores productivos de Bogotá, e investigar la asociación de estos perfiles con su desempeño innovador. Con el modelo y formulario de encuesta de Denison (1998, 2005), se tomo una muestra de 141 empresas pertenecientes a cuatro subsectores para estimar los perfiles sectoriales de cultura organizacional. Contrariamente a lo esperado, en este estudio, no se encontraron diferencias significativas entre los perfiles generales de cultura corporativa de los sectores, aunque se encontraron diferencias en los grados de asociación entre innovación y las variables de cultura organizacional de cada sector. Sí se encontraron diferencias en los puntajes de las variables de cultura organizacional de las empresas innovadoras frente a las poco innovadoras que pertenecen a los mismos sectores. Finalmente se confirma asociación estadística entre las características de cultura organizacional e innovación, encontrando que la discriminación por sectores también explica la innovación.
\end{abstract}

Palabras clave: Innovación, Facultamiento, Involucramiento, Adaptabilidad, Cultura corporativa, Asociación.

\section{ORGANIZATIONAL CULTURE: SECTORAL APPROXIMATION IN BOGOTÁ}

\begin{abstract}
This research sought to identify the profiles of organizational culture in four productive sectors of Bogotá, and research the association of these profiles with their innovational performance. With the model and survey form of Denison $(1998,2005)$, a sample of 141 companies which belong to 4 subsectors was made to estimate the sectoral profiles of organizational culture. Contrary to what was expected in the study, there was no evidence of significant differences among general profiles or corporation culture of sectors, although there were differences in the association degrees between innovation and organizational culture variables in each sector. There were differences in the score of organizational culture variables of innovating companies in relation to those less innovating enterprises. Finally, there is statistical association among organizational cultures and innovation characteristics, finding that the discrimination by sectors also explains innovation.
\end{abstract}

Keywords: Innovation, Empowerment, Involving, Adaptability, Corporative culture, Association.

\footnotetext{
* Artículo de investigación, producto del proyecto "Dinámica internacional y espacialidad de los clúster en Bogotá", adscrito al Centro de Investigación de la Escuela de Negocios, Fundación Universitaria Konrad Lorenz. Bogotá, Colombia, Grupo de investigación: Desarrollo local, transformación productiva y Competitividad- Clasificación C de Colciencias. Proyecto desarrollado en el año 2012.

** Profesor de la Fundación Universitaria Konrad Lorenz. Economista U.J. Magister en Economía U.N. Especialista en Evaluación Social de Proyectos UNIANDES. Candidato a Doctor en Análisis Económico UNED. Correo electrónico: ignacio.gomezr@konradlorenz.edu.co

**** Profesor de la Universidad de la Sabana-EICEA. Licenciado en Educación: U. San Buenaventura. Magister en Administración. U. del Valle. Master of Arts: U. de Chicago. Correo electrónico: rafael.ricardo@unisabana.edu.co
} 


\title{
CULTURA ORGANIZACIONAL: APROXIMAÇÃO SETORIAL EM BOGOTÁ
}

\begin{abstract}
Resumo
Este trabalho procurou identificar os perfis de cultura organizacional em quatro setores produtivos de Bogotá, e pesquisar a associação destes perfis com seu desempenho inovador. Com o modelo e o questionário de Denison (1998, 2005), tomou-se uma mostra de 141 empresas pertencentes a quatro subsectores para estimar os perfis setoriais de cultura organizacional. Contrariamente ao esperado, neste estudo, não se encontraram diferenças significativas entre os perfis gerais de cultura corporativa dos setores, mesmo havendo encontrado diferenças nos graus de associação entre inovação $e$ as variáveis de cultura organizacional de cada setor. Encontraram-se diferenças nas pontuações das variáveis de cultura organizacional das empresas inovadoras frente àquelas pouco inovadoras que pertencem aos mesmos setores. Finalmente se confirma a associação estatística entre as características de cultura organizacional e inovação, encontrando-se que a separação por setores também explica a inovação.
\end{abstract}

Palavras chave: Inovação, Facultamento, Envolvimento, Adaptabilidade, Cultura corporativa, Associação.

Gómez, I. \& Ricardo, R. (2012) Cultura organizacional: aproximación sectorial en Bogotá. En: Revista de la Facultad de Ciencias Económicas de la Universidad Militar Nueva Granada. rev.fac.cienc. econ, $\mathrm{XX}(2)$.

JEL: M31, M33.

\section{Introducción}

En este artículo se indaga y se descubre como la cultura organizacional es determinante de la innovación de las empresas. Se describen y se demuestran las relaciones entre los perfiles de cultura organizacional de varios sectores y las relaciones entre estas variables y la innovación. Aunque en las dos últimas décadas abundan los trabajos teóricos sobre los factores explicativos de la innovación como la inversión, la tecnología, los gastos en investigación y desarrollo, la formación de capital humano, los estudios sobre factores internos de las organizaciones como la cultura organizacional y la innovación no son tan abundantes.

Estudiar la cultura organizacional diferenciando por sectores contribuye al conocimiento de las empresas y sus vínculos con la innovación. Con gráficos pero especialmente con ejercicios estadísticos y economé- tricos se describe y comprueba la asociación entre la innovación con las variables y perfiles de cultura organizacional en diferentes subsectores de Bogotá.

\section{Metodología}

Se encontraron los perfiles culturales de organizaciones pertenecientes a cuatro sectores productivos en la ciudad de Bogotá, Colombia, habiendo aplicado la encuesta sobre cultura organizacional de Daniel Denison y sus asociados, denominada DOCS ${ }^{1}$. Con la participación de ciento cuarenta y una empresas bogotanas de diferentes sectores productivos (de acuerdo a la clasificación CIIU 3 1A), se estimó el perfil de cultura organizacional habiendo procesado 9.497 encuestas. Participaron empresas de los sectores comercio, reparación de automotores y enseres domésticos, se trabajaron 32 empresas. De la industria manufacturera 67 organizaciones. Pertenecientes al sector de transporte, almacenamiento y comuni-

4 Survey o encuesta ya probada en más de 5000 empresas de diferentes sectores, y 35 países de diferentes continentes. Extraída de: http://www.denisonconsulting.com/search_results.aspx?IndexCatalogue=General\&SearchQuery=survey 
caciones 20 empresas. Del sector inmobiliario, empaques y alquileres 22 firmas.

Se estimaron los perfiles de cada empresa a partir de muestras estadísticamente representativas del total de empleados, asumiendo un error del 5\%. La encuesta utilizada se vale de 60 ítems bajo la escala de likert (con cinco opciones de respuesta) para clasificar en 12 índices, cuatro rasgos, y cuatro sesgos, los perfiles cultura organizacional. Con siete preguntas adicionales se examinan diferentes indicadores de desempeño como la innovación. Con participación voluntaria, los criterios de selección fueron su localización en Bogotá y el registro de la firma. Se clasificaron sectorialmente a las empresas y se realizaron análisis gráfico y estadístico-econométrico.

\section{Marco de referencia}

\subsection{Estado del arte}

Como proceso de cambio Innovar es convertir ideas creativas en productos, procesos o servicios exitosos en los mercados. Usualmente se diferencian las innovaciones tecnológicas de las "no tecnológicas". Las primeras implican productos, servicios o procesos nuevos o mejorados, gracias a los cambios tecnológicos, mientras que las segundas consisten en nuevas formas de organización o gestión de las firmas o en cambios en el mercado.

Durante muchos años la teoría económica ha buscado explicaciones al crecimiento por medio de la acumulación de capital y variables como el ahorro, $\mathrm{I}+\mathrm{D}$, la productividad del capital y la financiación. Entre los factores que explican el crecimiento indudablemente la innovación juega un papel importante y los diferentes caminos que muestran los países, están vinculados con las distintas capacidades de adaptación a los cambios estructurales, "pero, en especial, derivan de la desigual capacidad innovadora en lo relativo a los productos, procesos y organización de la producción. Capacidad que no es puramente tecnológica, sino también institucional y social (...) La evidencia histórica pone de manifiesto que el desarrollo económico y el crecimiento a largo plazo no son posibles como mero subproducto del aumento de la cantidad cuantitativa de los factores de producción, sino que requiere de cambios estructurales, tanto del lado de la oferta (nuevos productos, nuevos sectores, nueva organización productiva), como del lado de la demanda (nuevas necesidades, nuevos mercados), y también en las relaciones e instituciones sociales -conflicto y colaboración entre los agentes económicos, distribución de la renta, políticas públicas- (...) (Vence, 2007, 19-21).

"Los negocios de hoy están funcionando en entornos altamente competitivos y rápidamente cambiantes. Esto hace que sus capacidades para innovar sean cruciales para su supervivencia a largo plazo. Por lo tanto, entender cómo sus culturas apoyan o entorpecen el proceso de innovación es crítico si quieren permanecer competitivos en mercados exigentes. Para ser verdaderamente innovadora, una organización no sólo debe ser creativa, sino también ser capaz de implementar exitosamente esas ideas creativas. Debido a esta distinción, los comportamientos, valores y normas organizacionales que promueven la producción de ideas creativas dentro de una organización pueden diferir de aquellos que estimulan la implementación exitosa de las ideas creativas, o la innovación como tal (Flynn \& Chatman, 2001). En consecuencia las características de perfiles culturales que impulsan a cada una pueden diferir también" (Denison Consulting, 2008, 2).

Para conseguir las dinámicas que desatan los procesos de innovación, se deben identificar e investigar los factores ambientales de los contextos empresariales que inciden en la creatividad para identificar las cualidades organizacionales que impulsan o inhiben la actitud creativa en individuos y grupos (Gisbert, 2005). Uno de esos factores es precisamente la cultura organizacional. Con frecuencia se afirma que el fracaso o el éxito de los cambios organizacionales de deben a los aspectos de la cultura organizacional tales como esfuerzos para mejorar las capacidades creativas e innovadoras. A pesar de la presencia de herramientas, técnicas y estrategias, el fracaso puede ocurrir porque la cultura fundamental de la organización permanece igual (Linnenluecke \& Griffiths, 2009, 3).

Saber sobre cultura, creatividad e innovación demanda conocer los perfiles culturales que impactan la creatividad y la innovación. El mejor conocimien- 
to de los perfiles culturales facilita el éxito de los cambios organizacionales que mejoran las capacidades creativa e innovadora. En esta dirección, desarrollar culturas organizacionales que originen ambientes creativos y que gerencien procesos creativos, cimienta la innovación y el mejoramiento continuo (Martensen \& Dahlgaard, 1999). La cultura organizacional es entonces determinante en los procesos creativos e innovadores de las organizaciones y estimula o limita el uso de las capacidades individuales y colectivas para el desarrollo de las innovaciones.

La cultura organizacional conducente al desarrollo de las innovaciones desarrolla empresas competitivas en el presente, y posibilita los cambios que deban ocurrir con el transcurrir de los tiempos para la adecuación y crecimiento de mentes creativas que construyan dinámicas del fenómeno de destrucción creadora en que yacen en las bases de la innovación y del sistema capitalista mismo (Schumpeter, 1942).

\subsection{Desempeño y cultura organizacional}

La cultura organizacional aporta los valores, creencias y principios que sirven como fundamento para el sistema gerencial de una organización, como también los patrones de comportamientos o prácticas que ejemplifican y refuerzan esos valores, creencias y supuestos básicos (Denison, 1990). La cultura de una organización genera expectativas que dirigen a los individuos a comportarse de forma consistente con esa cultura. Esta relación es la base que sustenta la influencia de la cultura en el desempeño (Gregory, Harris, Armenakis \& Shook, 2009, 673).

El modelo de Denison y sus asociados, sobre cultura organizacional y desempeño se asienta en el enfoque clásico de Schein (1985) el cual divide la cultura en tres niveles. Al nivel más profundo, los supuestos básicos yacen a la raíz de la cultura y son creencias, percepciones, pensamientos y sentimientos inconscientes que se dan por garantizados y que rara vez se cuestionan. En segundo lugar, aparecen los valores declarados formalmente que se derivan de esos supuestos básicos y que justifican las estrategias, objetivos y filosofías corporativas. Finalmente, al nivel más visible están los artefactos, o sea las estructuras, procesos, conductas y normas (Schein, 2010).
Aunque los niveles más profundos de la cultura son difíciles de medir, ellos proporcionan el fundamento desde el cual se proyectan la conducta y las acciones humanas dentro de las organizaciones. Según Denison, Hooijberg, Lane \& Lief (2012), las creencias y supuestos básicos sobre la organización y su gente, el cliente, el mercado y la industria, y la proposición básica de valor de la empresa, generan un tejido lógico que compacta a la organización.

El modelo de Denison et al. (2012) integra teórica $y$ operacionalmente los niveles intangibles y tangibles de la cultura, porque facilita la articulación entre cultura, comportamiento y desempeño organizacional. En consecuencia, en el modelo se consigue un diagnóstico sistémico que permite estimar los perfiles de cultura de las organizaciones, y se pueden establecer los cambios comportamentales que esa cultura requiera en función de un mejor desempeño (Baker, 2004). Este esquema se clasifica entonces en la vertiente teórica que interpreta a la cultura como un activo competitivo susceptible de ser medido, intervenido y gerenciado hacia el desempeño organizacional.

\subsection{El modelo de Denison para el diagnóstico científico de la cultura organizacional en función del desempeño}

Según Denison et al. (2012) la investigación en las tres últimas décadas ha demostrado que la cultura organizacional impacta el desempeño empresarial mediante la creación de un sentido de misión y dirección; la construcción de un alto nivel de adaptabilidad y flexibilidad; el estímulo al involucramiento y compromiso de la gente; y el establecimiento de una consistencia institucional fuertemente enraizada en un conjunto de valores nucleares. Estas cuatro características culturales explican la diferencia entre las organizaciones de alto y bajo desempeño. Los estudios han examinado la conexión entre las cuatro características básicas del modelo -misión, adaptabilidad, involucramiento, y consistencia - y medidas de desempeño tales como rentabilidad, crecimiento en ventas, calidad, innovación, y valor en el mercado. Cada característica se mide por medio de tres índices, y cada índice se mide con cinco ítems del cuestionario. 
Dicho modelo se desarrolló a partir de investigaciones realizadas durante más de 20 años en más de 3.000 organizaciones y con más de 100.000 personas encuestadas (Denison, 1990; Denison \& Mishra, 1995; Denison \& Neale, 1996). En la Ilustracion 1 se representan las características e índices que constituyen la cultura organizacional (Mobley, Wang \& Fang, 2005, 133). Los cuatro cuadrantes del modelo representan las cuatro características básicas de cualquier cultura organizacional. Cada cuadrante incluye tres índices de comportamientos o prácticas que se conectan con cada una de las características. Las características y los índices se representan en términos de dos dimensiones subyacentes, flexibilidad versus estabilidad sobre el eje horizontal y del foco externo y del foco interno sobre el eje vertical. A continuación se describen las cuatro características culturales de las organizaciones efectivas con referencia a su fundamentación en la literatura sobre estudios organizacionales:

Ilustración 1. El Modelo de Cultura Organizacional de Denison²

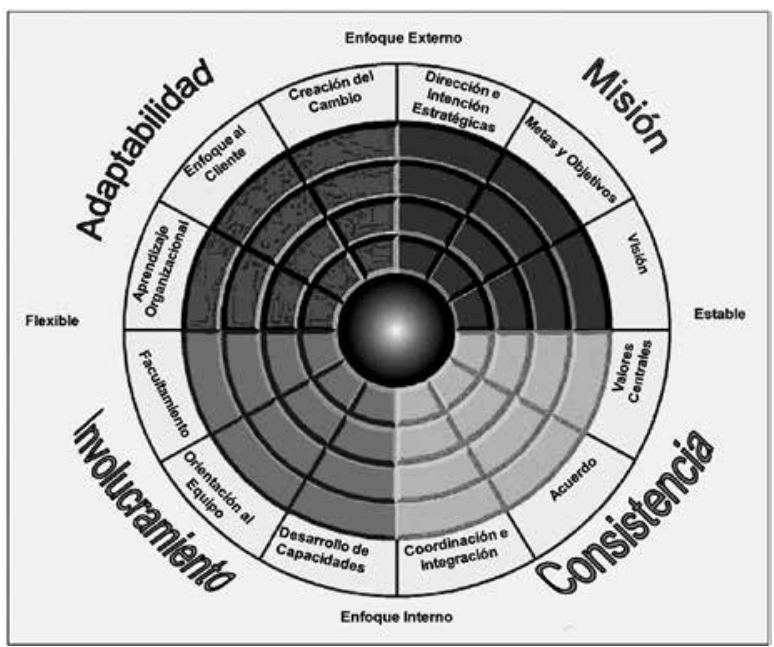

\subsubsection{Involucramiento}

Las organizaciones efectivas facultan, empoderan a su gente, que se construye a sí misma alrededor de los equipos, y desarrollan la capacidad humana a todos los niveles (Becker, 1964; Lawler, 1996; Likert,
1961). Los miembros de la organización se comprometen con su trabajo y sienten que poseen una parte de la organización. Las personas en todos los niveles, sienten que tienen al menos alguna influencia en las decisiones que afectan sus trabajos y que estos están directamente conectados con los objetivos de la organización (Spreitzer, 1995). El involucramiento se mide con tres índices: facultamiento, orientación al equipo y desarrollo de capacidades.

\subsubsection{Consistencia}

Las organizaciones son efectivas en razón de su consistencia e integración interna (Davenport, 1993; Saffold, 1988). El comportamiento de las personas se fundamenta en un conjunto de valores centrales (core values), los líderes y sus seguidores poseen la habilidad de lograr acuerdos (aun cuando existan diversos puntos de vista), y las actividades de la organización están bien coordinadas e integradas (Block, 1991).

Las organizaciones que poseen fortalezas en esta característica tienen una cultura distintiva y que influye marcadamente en el comportamiento de las personas. Un sistema compartido de supuestos, creencias $y$ valores funciona como un sistema de control internalizado. La consistencia es pues una poderosa fuerza de estabilidad e integración interna que resulta de un marco mental (mindset) común y de un alto grado de conformidad (Senge, 1990). La consistencia se conforma con los siguientes índices: valores centrales, acuerdo y coordinación e integración.

\subsubsection{Adaptabilidad}

Las organizaciones adaptables son impulsadas por sus clientes, asumen riesgos y aprenden de sus errores. Tienen capacidad y experiencia en la creación del cambio (Senge, 1990; Stalk, 1988) y mejoran permanentemente su capacidad para generar y entregar valor a sus clientes. Las organizaciones fuertes en adaptabilidad generalmente experimentan crecimiento en las ventas y en su participación del mercado. Esta característica se estima con los índices de creación de cambio, aprendizaje organizacional y enfoque en el cliente.

2 Fuente: Denison, et al. (2012). 


\subsubsection{Misión}

Las organizaciones exitosas frecuentemente tienen claro sentido de propósito, dirección que define las metas organizacionales y los objetivos estratégicos y además expresa la visión de futuro de la organización (Mintzberg, 1987; Ohmae, 1982; Hamel \& Prahalad, 1994). Esta característica se estima por medio de los índices de: dirección e intención estratégica, metas y objetivos, y visión.

\subsection{Relación entre características culturales y desempeño organizacional}

El modelo conceptual sobre cultura y desempeño y la encuesta aplicada en la investigación reportada en este artículo se desarrollaron para operacionalizar una teoría de efectividad cultural que se enfoca en las cuatro características claves del desempeño organizacional: involucramiento, adaptabilidad, consistencia y misión (Denison et al., 2012).

De acuerdo con Denison (Denison, 1982, 1984, 1990; Denison \& Mishra, 1995), los estudios inicialmente se centraron en la conexión entre cultura corporativa y efectividad organizacional. De aquí surgió el modelo conceptual orientado a sistematizar los resultados de la investigación acerca de las características culturales de organizaciones efectivas (Denison et al., 2012).

Los estudios más recientes han revisado la conexión entre cultura y desempeño a través del tiempo (Smerek \& Denison, 2007; Boyce 2010). En palabras de Denison et al. $(2012,191)$ :
"Conjuntamente estos estudios apoyan la idea de que las organizaciones de más alto desempeño encuentran maneras de facultar e involucrar a su gente (involucramiento), facilitan las acciones coordinadas y promueven la consistencia entre las conductas y los valores centrales de la empresa (consistencia), traducen en acción las demandas del ambiente organizacional (adaptabilidad), y proveen un sentido claro de propósito y dirección (misión)."

Denison \& Mishra (1995) estudiaron la correlación entre las características culturales del modelo (involucramiento, consistencia, adaptabilidad y misión) y un conjunto de medidas de desempeño organizacional. Misión y consistencia (estabilidad) impactan a las medidas de desempeño financiero tales como retornos sobre la inversión, los activos, y retorno sobre las ventas. Por su parte, involucramiento y adaptabilidad (flexibilidad), impactan más el desarrollo de productos y servicios, a la innovación. Esto quiere decir que la innovación en productos y servicios y el impulso a la creatividad responden a las necesidades cambiantes de clientes y empleados.

Adaptabilidad y misión (enfoque externo) impactan al ingreso y al crecimiento en ventas, así como a la participación en el mercado. Por su parte, involucramiento y consistencia (foco interno) se reflejan en los indicadores de calidad de productos y servicios, retorno sobre inversión y satisfacción de los empleados (Denison \& Mishra, 1995). La Tabla 1 resume las conexiones entre las características culturales y los indicadores de desempeño organizacional:

Tabla 1. Relaciones entre rasgos de cultura organizacional y desempeño ${ }^{3}$

\begin{tabular}{|c|c|c|c|c|c|}
\hline $\begin{array}{l}\text { Rentabilidad. } \\
\text { Retorno sobre } \\
\text { activos }\end{array}$ & $\begin{array}{c}\text { Crecimiento de } \\
\text { ingresos/ crecimiento } \\
\text { en ventas }\end{array}$ & $\begin{array}{l}\text { Participación en } \\
\text { el mercado }\end{array}$ & Innovación & $\begin{array}{l}\text { Calidad de } \\
\text { productos y } \\
\text { servicios }\end{array}$ & $\begin{array}{c}\text { Satisfacción de los } \\
\text { empleados }\end{array}$ \\
\hline Misión & Misión & Misión & & & [Misión] \\
\hline Involucramiento & & & Involucramiento & Involucramiento & Involucramiento \\
\hline Adaptabilidad & Adaptabilidad & Adaptabilidad & Adaptabilidad & & [Adaptabilidad] \\
\hline Consistencia & & & & Consistencia & Consistencia \\
\hline
\end{tabular}

3 Fuente: Denison \& Neale (1996). 


\subsection{Características culturales y desempeño innovador}

Refiriéndose a la creatividad y la innovación se ha encontrado que las empresas con altos puntajes en involucramiento suelen estimular los sentidos de libertad y autonomía que favorecen generar ideas. Las organizaciones con estas características suelen organizarse en torno a equipos de trabajo cooperativo con responsabilidades mutuas. Bajo estas formas de trabajo se deben integrar los trabajadores o intercambiando ideas y compartiendo las responsabilidades. En estos ambientes de interacciones que combinan la formalidad y la informalidad se discuten las ideas sin temores a censuras viviendo ambientes de confianza que conducen a la creatividad y la innovación.

Las firmas con altos puntajes en la característica de involucramiento en su cultura organizacional, construyen permanentemente sentido de pertenencia de sus trabajadores en sus equipos de trabajo y en la organización, a la vez que desarrollan capacidades de trabajo en equipo, en el cual se pueden sembrar y cosechar las variadas ideas creativas de quienes pertenecen al grupo, al ser alimentadas y discutidas en los equipos de trabajo. Estas características estimuladoras de la creatividad, la participación y el aprendizaje estimulan la automotivación y la motivación externa y mayor involucramiento.

La adaptabilidad es crucial para fomentar la creatividad, el trabajo en equipo y la innovación. Las empresas que se focalizan en el mercado y en el cliente desarrollan capacidades para percibir y crear ideas que favorecen el aprendizaje y su aprovechamiento para mejorar sus interacciones con clientes, colaboradores y competidores. Estas empresas con altos puntajes en involucramiento y adaptabilidad estimulan a sus trabajadores a asumir riesgos calculados y a interactuar con sus clientes y proveedores con canales adecuados de comunicación que conducen a resultados efectivos.

Vistos los rasgos de involucramiento y adaptabilidad como características que favorecen y alimentan la creatividad, la participación, y el aprendizaje, estos rasgos de cultura organizacional deben encontrar otros rasgos con altos puntajes que permitan llevar exitosamente a la realidad las concreciones de las ideas creativas, es decir implementarlas y dirigirlas para que las organizaciones puedan nutrirse de los beneficios de las innovaciones. En el modelo de Denison et al. (2012) estos atributos para concretar la creatividad se hallan en el rasgo de cultura organizacional llamado misión.

En esta característica o rasgo de cultura organizacional se incluyen los aspectos de dirección estratégica, las definiciones de objetivos y metas compartidos, así como la visión y misión claramente definidos, y una identidad organizacional fuerte. La claridad en estos aspectos conduce a que las nuevas ideas que se desarrollen estén en la misma dirección que orientan las directivas de la organización y hacia las cuales se está moviendo (West \& Far, 1990).

Las claridades en metas y dirección señalan los caminos retadores de convertir "ideas" o tal vez sueños en productos y servicios reales. "Si las organizaciones poseen la creatividad pero son incapaces de enfocarse en una dirección común, no podrán trasladar sus ideas creativas en ofertas de negocio viables. [...] La Adaptabilidad es importante para la generación de ideas creativas, y continúa desempeñando también un papel importante en la ejecución. La fortaleza en esta característica asegura que la organización escoja implementar ideas que el mercado valore y necesite. [...] Las organizaciones fuertes en Adaptabilidad tienden a involucrarse en asumir riesgos después del aprendizaje: ellas aprenden de sus éxitos y sus fracasos y de los éxitos y fracasos de otros." (Denison Consulting, 2008, 2).

El rasgo consistencia es también relevante para transformar las ideas en los procesos de innovación. Aun reuniendo las condiciones favorables a la innovación de unos rasgos culturales, al tener limitaciones para llegar a acuerdos o consensos dentro de la firmas se pueden truncar las posibilidades de innovar desde las mismas condiciones propias de la organización. A manera de hipótesis puede plantearse que:

"La fortaleza en las características de Adaptabilidad y Misión, enfocadas a lo externo, son más ventajosa para la innovación que 
la fortaleza en las características internas de Involucramiento y Consistencia. No obstante, aunque las organizaciones se enfoquen en las características externas, todas las características del modelo de Denison juegan un papel en cómo la organización innova. Involucramiento y Adaptabilidad son importantes para estimular la creatividad y Misión y Consistencia son importantes para la ejecución y la implementación que resultan en la innovación. Aquellas organizaciones que sean capaces de balancear los aspectos de sus culturas que generan creatividad con la capacidad de implementar ideas creativas serán las más proclives a continuar innovando y mantenerse competitivas" (Denison Consulting, 2008, 4).

\subsection{Estudios internacionales basados en el modelo de Denison}

El modelo y la encuesta de Denison han sido utilizados en estudios sobre la relación entre la cultura organizacional y el desempeño de las firmas en diferentes partes del mundo (Mobley, Wang \& Fang, 2005; Denison, Haaland \& Goelzer, 2003a, 2003b; Fey \& Denison, 2003).

Los resultados a nivel internacional han mostrado asociaciones diferentes según el tipo de indicador de desempeño. Para la innovación, la asociación más estrecha que se ha encontrado mediante coeficientes de correlación ha sido con las características de adaptabilidad e involucramiento. Expresada en términos de sesgos, el mayor vínculo se obtiene en el sesgo de flexibilidad, que está compuesto por estas dos características, aunque el sentido de misión juega también su papel.

\section{Análisis de datos y resultados en Bogotá}

\subsection{Perfiles de cultura organizacional: aproximación sectorial}

En el área sombreada de la Tabla 2 se muestran los perfiles de cultura organizacional definidos por los cuatro rasgos o características de cultura organizacional (involucramiento, misión, adaptabilidad y consistencia) para cada uno de los cuatro sectores considerados en la investigación. Esta información se amplía al incluir tanto los índices como los sesgos.

Contrariamente a lo esperado no se encontraron grandes diferencias entre los perfiles de cultura organizacional entre los cuatro sectores estudiados. Las valoraciones promedio de cada una de las variables a nivel de índices, características y sesgos, fueron muy similares entre sectores tal como puede observarse en el Tabla 2.

Las empresas estudiadas en esta investigación pertenecen a diferentes subsectores de la economía, agrupadas con criterios de la clasificación CIIU, de acuerdo a lo enunciado en la metodología. Cabe anotar que la relativa igualdad en los puntajes de los rasgos de cultura organizacional en cada empresa es conveniente para el armónico desarrollo de las actividades. Ello no significa que los puntajes promedio y entre empresas o sectores no pudieran ser diferentes. De hecho entre empresas hay diferencias considerables.

Las culturas corporativas sectoriales absorben condiciones de las dimensiones geográfica (internacional, nacional, regional y local) ya que "la cultura empresarial no existe de manera independiente, separada de la cultura nacional o de la cultura vigente en su entorno geográfico más próximo. Así las culturas empresariales de países culturalmente homogéneos incorporarán elementos comunes de una cultura de ámbito general, mientras que en el caso de países culturalmente heterogéneos, las culturas empresariales presentarán mayores diferencias entre sí" (Morcillo, 2007, 18-19).

En las empresas que participaron de la investigación, el rasgo con mayor puntaje en tres de los cuatro sectores (industria manufacturera; comercio, reparación de autos y enseres; y transporte, almacenamiento $y$ comunicaciones) es misión. El rasgo con menor puntaje es consistencia en los cuatro sectores. En general, puede afirmarse que en los tres sectores, las organizaciones saben para donde van pero no se articulan bien las acciones para conseguir lo que 
Tabla 2. Perfiles de cultura organizacional por sectores ${ }^{4}$

\begin{tabular}{|l|c|c|c|c|}
\hline \multicolumn{1}{|c|}{ CULT.ORGISECT } & $\begin{array}{c}\text { INDUSTRIA MA- } \\
\text { NUFACTURERA }\end{array}$ & $\begin{array}{c}\text { CIO. REPARACIÓN DE } \\
\text { AUTOS, ENSERES }\end{array}$ & $\begin{array}{c}\text { TRANSP. ALMAC. } \\
\text { COMUNICACIONES }\end{array}$ & $\begin{array}{c}\text { INMOBILIARIAS EMPA- } \\
\text { QUES; ALQUILERES }\end{array}$ \\
\hline EMPODERAMIENTO & 3,670 & 3,665 & 3,654 & 3,663 \\
\hline ORG. GRUPOS & 3,713 & 3,696 & 3,703 & 3,653 \\
\hline DESARROLLO DE CAPACIDADES & 3,515 & 3,547 & 3,557 & 3,513 \\
\hline VALORES CENTRALES & 3,668 & 3,727 & 3,659 & 3,650 \\
\hline ACUERDO & 3,469 & 3,437 & 3,461 & 3,419 \\
\hline COORDINACIÓN & 3,457 & 3,406 & 3,434 & 3,398 \\
\hline CREACION DE CAMBIO & 3,462 & 3,405 & 3,460 & 3,378 \\
\hline FOCO CLIENTE & 3,533 & 3,566 & 3,611 & 3,486 \\
\hline APRENDIZAJE & 3,600 & 3,631 & 3,680 & 3,535 \\
\hline DIR ESTRATE & 3,626 & 3,686 & 3,659 & 3,536 \\
\hline OBJETIV METAS & 3,714 & 3,738 & 3,702 & 3,600 \\
\hline VISIÓN & 3,533 & 3,477 & 3,512 & 3,477 \\
\hline INVOLUCRAMIENTO & 3,633 & 3,636 & 3,638 & 3,610 \\
\hline CONSISTENCIA & 3,531 & 3,523 & 3,518 & 3,489 \\
\hline ADAPTABILIDAD & 3,565 & 3,608 & 3,630 & 3,490 \\
\hline MISION & 3,653 & 3,669 & 3,659 & 3,544 \\
\hline FLEXIBILIDAD & 3,599 & 3,622 & 3,634 & 3,550 \\
\hline ESTABILIDAD & 3,592 & 3,596 & 3,589 & 3,516 \\
\hline FOCO EXTERNO & 3,609 & 3,639 & 3,645 & 3,517 \\
\hline FOCO INTERNO & 3,582 & 3,580 & 3,578 & 3,549 \\
\hline
\end{tabular}

desean. Consistencia encarna a los valores y a los patrones de comportamiento como los acuerdos, que bien integrados garantizarían encaminar las fortalezas empresariales hacia el desempeño.

En las empresas inmobiliarias, empaques y alquileres; involucramiento es el rasgo de mayor fortaleza. Frente a los demás sectores, en las empresas con mayores puntajes en éste rasgo, su personal asume compromisos con más responsabilidad. Aunque los perfiles de cultura organizacional de los cuatro sectores se muestran bastante equilibrados, como puede verse en la Tabla 2 , en cada perfil sectorial existen ligeros sesgos que se observan por los mayores valores al comparar estabilidad frente a flexibilidad y; foco externo frente a foco interno.
Los sesgos se definen por valores encontrados en los rasgos de la siguiente manera: primero, ligero sesgo hacia la flexibilidad y sesgo hacia el foco externo en los sectores de industria manufacturera comercio, reparación de automotores y enseres de uso doméstico, y el sector de inmobiliarias, empresariales y de alquiler. Estos sesgos favorecen el desempeño innovador. Segundo, ligero sesgo hacia la estabilidad y sesgo hacia el foco interno en el sector de Transporte almacenamiento y comunicaciones. Muestra una leve tendencia a favorecer el desempeño en rentabilidad financiera y satisfacción de los empleados.

\subsection{La cultura organizacional se asocia con la innovación en todos los sectores}

En seguida se muestran los gráficos de las empresas en los cuales se identifican las asociaciones entre los

\footnotetext{
4 Fuente: Elaboración de los autores a partir de encuestas primarias a empresas y cálculos propios.
} 
rasgos de cultura organizacional y el desempeño innovador para las empresas agrupadas en los diferentes sectores. El análisis grafico de estas asociaciones se observa en las representaciones de cada empresa con un punto, que corresponde con las puntuaciones obtenidas en las estimaciones de innovación y el rasgo respectivo localizadas en el plano cartesiano. Estas nubes de puntos representadas son reforzadas para su análisis por una línea de tendencia. Al examinar las Ilustraciones 3 a 5 se confirma la relación directa entre innovación y los mayores puntajes en los rasgos de cultura organizacional que tienen las empresas.

En los Tablas 3 a 6 se muestran los perfiles de cultura organizacional (rasgos y sesgos) de los cuartiles de las empresas clasificados por orden de innovación. De tal manera que se pueden contrastar en cada sector estudiado a los extremos de las empresas más innovadoras frente a las menos innovadoras.

Con el fin de examinar la asociación estadística entre los perfiles de cultura organizacional e innovación se presentan los coeficientes de correlación entre inno- vación y los índices, rasgos y sesgos de cultura organizacional. Para reconfirmar las asociaciones estadísticas entre la cultura organizacional en los diferentes sectores se hicieron primero ejercicios con el Alpha de Cronbach que permiten examinar la consistencia de la información discreta a nivel de los ítems que definen los rasgos de cultura organizacional, y como preámbulo del examen del fenómeno por medio del modelo logit ordenado.

\subsubsection{Estudio gráfico del perfil de cultura organizacional y contraste entre las empresas más y menos innovadoras en industria manufacturera}

En la Ilustración 2, las nubes de puntos representan el conjunto de empresas del sector manufacturero. Pueden observarse las relaciones existentes entre la innovación y variables de cultura organizacional de las empresas. Cada punto es una empresa y la línea de cada componente de la ilustración permite observar el tipo de relación existente entre innovación y los cuatro rasgos que definen la organizacional (ver Tabla 2).

Ilustración 2. Rasgos de cultura organizacional en la industria manufacturera ${ }^{5}$
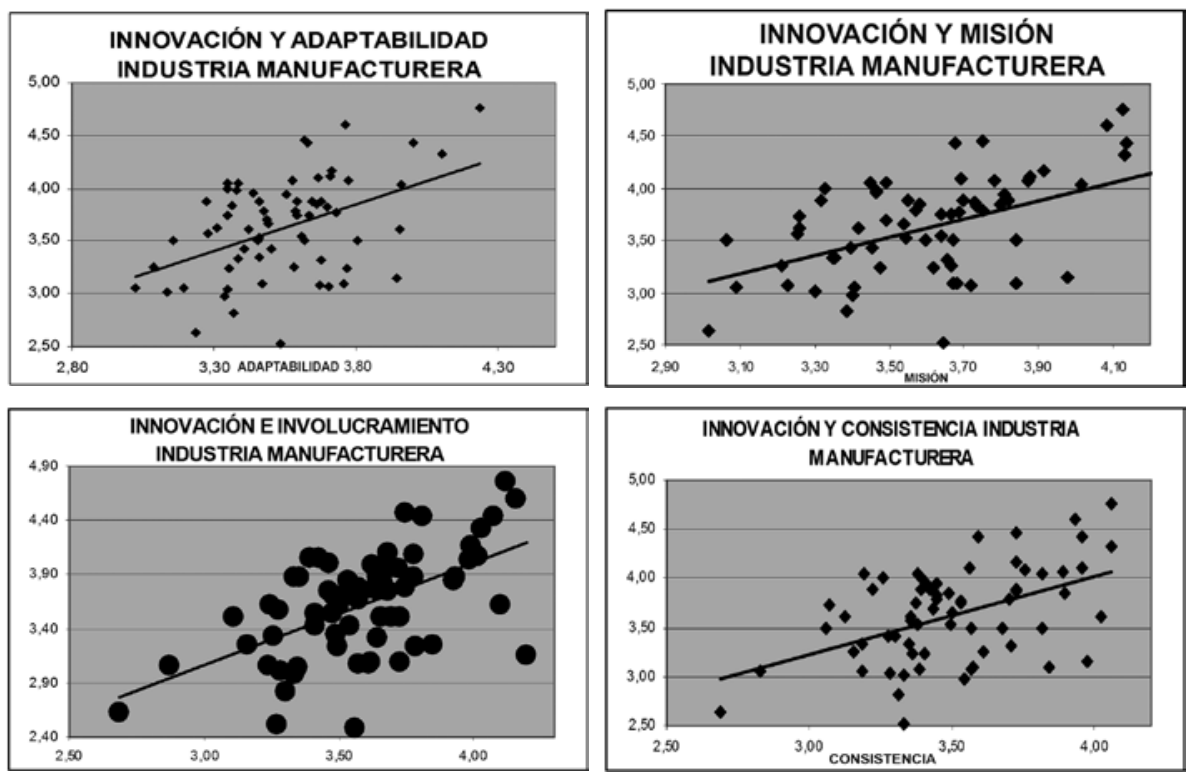

5 Fuente: Elaboración de los autores a partir de encuestas a empresas y cálculos propios. 
Estas nubes de puntos junto con la tendencia de pendiente positiva permiten concluir que a mayores puntajes de los rasgos de cultura organizacional se espera un mejor desempeño innovador. Sin embargo, perteneciendo las empresas al mismo sector productivo es claro que no todas las empresas son iguales y si bien hay muchas empresas que se encuentran relativamente cerca de la línea de tendencia, otras muchas se encuentran distantes. La observación general es que la relación es positiva entre innovación y los puntajes crecientes en los cuatro rasgos de cultura organizacional en las empresas de la industria manufacturera.

Al examinar los perfiles de cultura organizacional de las empresa innovadoras y menos innovadoras de la industria manufacturera (según el primer y cuarto cuartil de la variable innovación) es claro que los promedios de los rasgos de involucramiento, consistencia, adaptabilidad y misión guardan una diferencia alrededor de entre dos y tres décimas.

Sin embargo, los promedios de clasificación en innovación distan en algo más de 12 décimas. Con lo cual puede pensarse que no obstante la desviación estándar, la innovación es sensible a pequeños cambios en los rasgos de cultura organizacional de las empresas de la industria manufacturera. La mayor desviación estándar está en la variable involucramiento y la menor en adaptabilidad.
En los respectivos segmentos de las empresas más y menos innovadoras los sesgos de flexibilidad frente a estabilidad y foco externo frente a interno no presentan diferencias grandes, pero se esperaría que en las empresas innovadoras fuera mayor la flexibilidad. Pero entre empresas innovadoras y no innovadoras sí se observan diferencias de más de dos décimas.

\subsubsection{Estudio gráfico del perfil de cultura organizacional y contraste entre las empresas más y menos innovadoras en subsectores de comercio, reparación de autos, y enseres domésticos}

En la Ilustración 3 pueden verse las nubes de empresas y sus relaciones entre los rasgos respectivos de cultura organizacional e innovación. La relación que se observa entre involucramiento, consistencia, adaptabilidad y misión con la innovación es directa. A mayor puntuación de los rasgos es mayor la innovación de los subsectores de comercio, reparación de autos, y enseres domésticos.

Si bien por la observación directa de las pendientes de las líneas de tendencia se observa que no son iguales, ello lleva a preguntar sobre las diferentes sensibilidades de la innovación a los cambios en rasgos de cultura organizacional en los distintos sectores.

Tabla 3. Perfil de las empresas más y menos innovadoras en industria manufacturera ${ }^{6}$

\begin{tabular}{|l|c|c|c|}
\hline $\begin{array}{c}\text { INDUSTRIA } \\
\text { MANUFACTURERA }\end{array}$ & MÁS INNOVADORAS & $\begin{array}{c}\text { MENOS } \\
\text { INNOVADORAS }\end{array}$ & $\begin{array}{c}\text { DESVIAC. } \\
\text { ESTÁNDAR }\end{array}$ \\
\hline INNOVACION & 4,21 & 2,99 & 0,49 \\
\hline INVOLUCRAMIENTO & 3,83 & 3,46 & 0,30 \\
\hline CONSISTENCIA & 3,69 & 3,40 & 0,29 \\
\hline ADAPTABILIDAD & 3,68 & 3,47 & 0,24 \\
\hline MISIÓN & 3,78 & 3,52 & 0,27 \\
\hline FLEXIBILIDAD & 3,75 & 3,47 & 0,26 \\
\hline ESTABILIDAD & 3,73 & 3,46 & 0,27 \\
\hline FOCO EXTERNO & 3,73 & 3,50 & 0,25 \\
\hline FOCO INTERNO & 3,76 & 3,43 & 0,29 \\
\hline
\end{tabular}

6 Fuente: Elaboración de los autores a partir de encuestas a empresas y cálculos propios. 
En la Tabla 4 se comparan los perfiles de cultura organizacional de las empresas más innovadoras frente a las menos innovadoras, y también se observa que las diferencias de calificación en la variable de innovación es de alrededor de doce décimas, mientras que en los rasgos y sesgos se encuentran entre dos y tres décimas.
La mayor desviación estándar se encuentra en la variable de innovación y en el rasgo de involucramiento, mientras que en adaptabilidad, la desviación estándar es la menor.

Ilustración 3. Rasgos de cultura organizacional en subsectores de comercio, reparación de autos, y enseres domésticos ${ }^{7}$
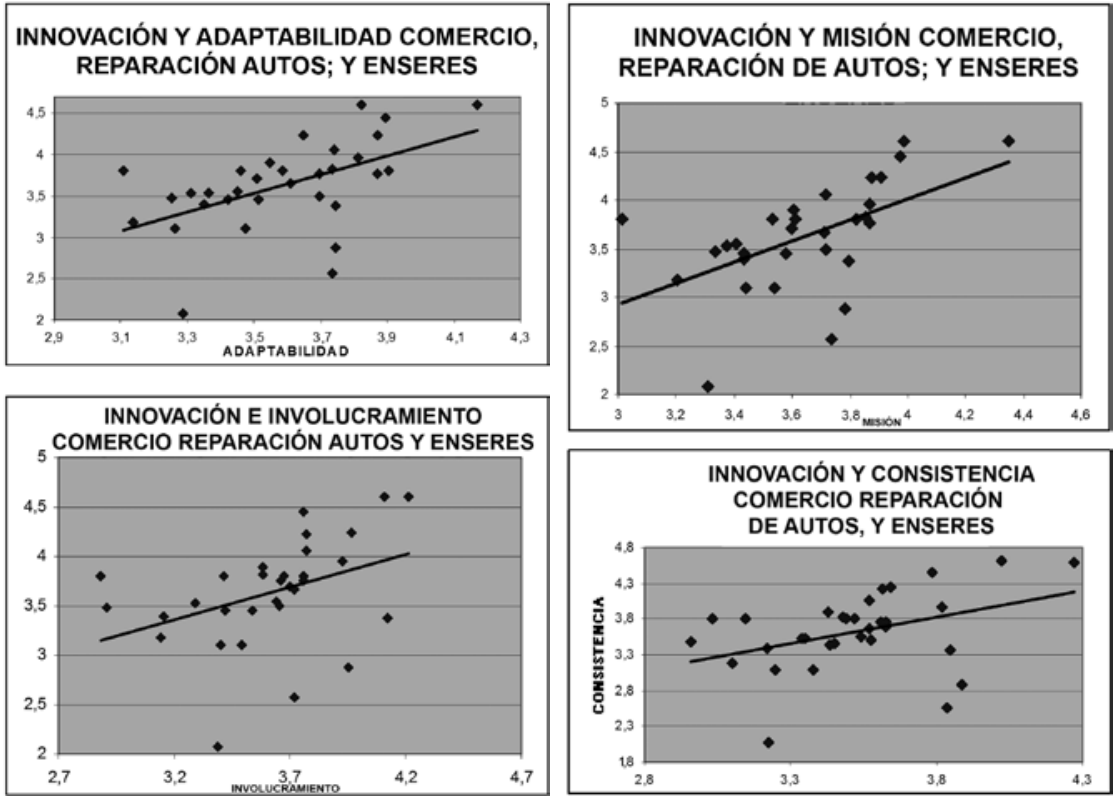

Tabla 4. Perfil de las empresas más y menos innovadoras en subsectores de comercio, reparación de autos, y enseres domésticos. ${ }^{8}$

\begin{tabular}{|l|c|c|c|}
\hline $\begin{array}{c}\text { CIO. REPARACIÓN } \\
\text { DE AUTOS, ENSERES }\end{array}$ & MÁS INNOVADORAS & $\begin{array}{c}\text { MENOS } \\
\text { INNOVADORAS }\end{array}$ & DESVIAC. ESTÁNDAR \\
\hline INNOVACION & 4,16 & 2,96 & 0,54 \\
\hline INVOLUCRAMIENTO & 3,82 & 3,55 & 0,32 \\
\hline CONSISTENCIA & 3,70 & 3,47 & 0,29 \\
\hline ADAPTABILIDAD & 3,80 & 3,47 & 0,25 \\
\hline MISIÓN & 3,89 & 3,53 & 0,27 \\
\hline FLEXIBILIDAD & 3,81 & 3,51 & 0,28 \\
\hline ESTABILIDAD & 3,80 & 3,50 & 0,27 \\
\hline FOCO EXTERNO & 3,85 & 3,50 & 0,26 \\
\hline FOCO INTERNO & 3,76 & 3,51 & 0,30 \\
\hline
\end{tabular}

Fuente: Elaboración de los autores a partir de encuestas a empresas y cálculos propios.

Fuente: Elaboración de los autores a partir de encuestas a empresas y cálculos propios. 
Al comparar flexibilidad y estabilidad en las empresas más innovadoras casi no existe diferencia, y tampoco existe casi diferencia en las empresas poco innovadoras. Aunque sí existen diferencias significativas esperadas entre los mismos sesgos al comparar a las empresas más innovadoras frente a las poco innovadoras.

\subsubsection{Estudio gráfico del perfil de cultura organiza- cional y contraste entre las empresas más y me- nos innovadoras en subsectores de transporte, almacenamiento y comunicaciones}

Al igual que en los casos anteriores se confirma la tendencia positiva o directa entre las puntuaciones de los rasgos de cultura organizacional e innovación. A mayores puntajes en los rasgos, mayores puntajes en la variable innovación en esta agrupación de empresas.

Ilustración 4. Rasgos de cultura organizacional en subsectores de transporte, almacenamiento y comunicaciones ${ }^{9}$
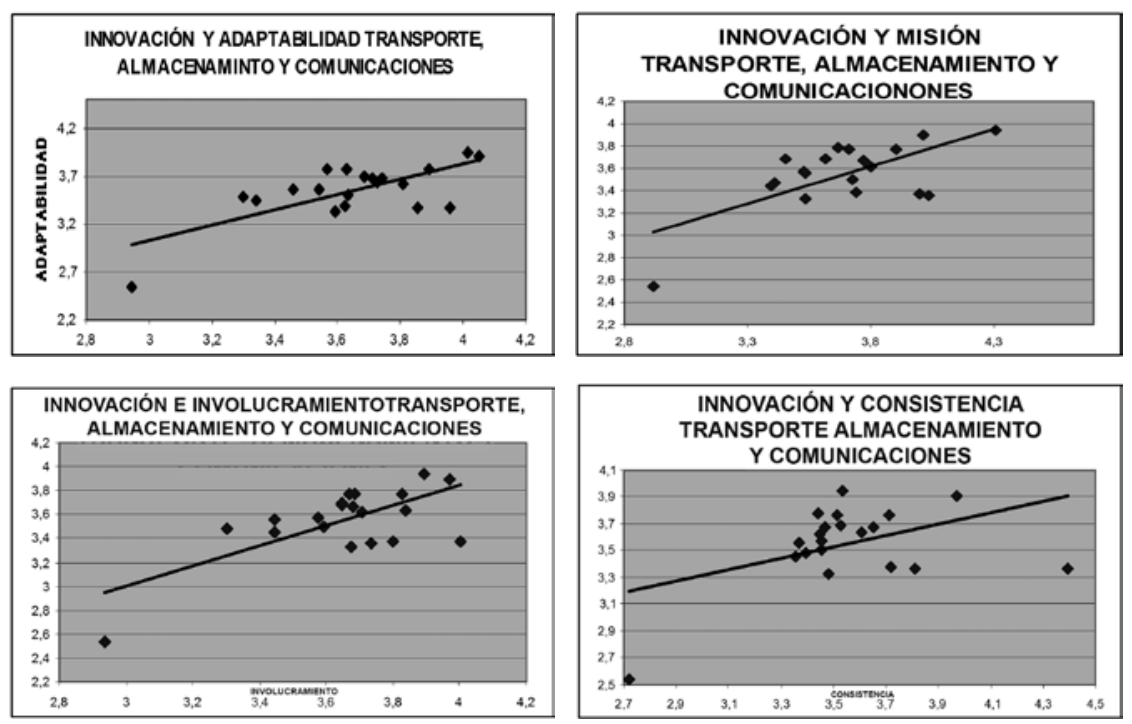

Tabla 5. Perfil de las empresas más y menos innovadoras en subsectores de transporte, almacenamiento y comunicaciones $^{10}$

\begin{tabular}{|l|c|c|c|}
\hline $\begin{array}{c}\text { TRANSP. ALMAC. } \\
\text { COMUNICACIONES }\end{array}$ & MÁS INNOVADORAS & MENOS INNOVADORAS & DESVIAC. ESTÁNDAR \\
\hline INNOVACION & 3,81 & 3,20 & 0,30 \\
\hline INVOLUCRAMIENTO & 3,78 & 3,63 & 0,24 \\
\hline CONSISTENCIA & 3,62 & 3,63 & 0,31 \\
\hline ADAPTABILIDAD & 3,81 & 3,59 & 0,26 \\
\hline MISIÓN & 3,87 & 3,64 & 0,30 \\
\hline FLEXIBILIDAD & 3,79 & 3,61 & 0,25 \\
\hline ESTABILIDAD & 3,74 & 3,63 & 0,29 \\
\hline FOCO EXTERNO & 3,84 & 3,62 & 0,27 \\
\hline FOCO INTERNO & 3,70 & 3,63 & 0,26 \\
\hline
\end{tabular}

9 Fuente: Elaboración de los autores a partir de encuestas a empresas y cálculos propios.

10 Fuente: Elaboración de los autores a partir de encuestas a empresas y cálculos propios. 
Sin embargo, cabe subrayar, que en este subsector las empresas innovadoras tienen un menor puntaje que en las otras agrupaciones de empresas (ver ilustración 4).

Las empresas mas innovadoras en la agrupación de los subsectores de transporte, almacenamiento y comunicaciones obtuvieron un puntaje promedio de 3,81, el más bajo frente a los otros subsectores. Pero también obtuvieron el puntaje más alto en las empresas poco innovadoras $(3,2)$ y la menor desviación estándar en la variable innovación al compararla con los otros subsectores considerados en la investigación (ver Tabla 5).

Las diferencias entre los puntajes de los rasgos entre las empresas innovadoras y poco innovadoras estuvieron alrededor de dos décimas y la característica involucramiento tuvo la menor desviación frente a las otras agrupaciones empresariales.

En las firmas más innovadoras el puntaje en el sesgo flexibilidad fue ligeramente superior al de estabilidad y el foco externo ligeramente superior al foco interno. En las empresas poco innovadoras ocurre lo contrario. Esto es consistente con lo señalado por la teoría.

\subsubsection{Estudio gráfico del perfil de cultura organizacional y contraste entre las empresas más y menos innovadoras en subsectores de inmobiliarias, empaques y alquileres}

Las nubes de puntos de las empresas que vinculan a sus puntajes en innovación y los respectivos rasgos de cultura organizacional permiten una vez más confirmar la relación directa existente entre las variables para la agrupación de empresas de los subsectores e inmobiliarias, empaques y alquileres (ver Ilustración 5).

La desviación estándar de la innovación del grupo de empresas de los subsectores de inmobiliarias, empaques y alquileres, es menor que en los grupos de empresas de los subsectores de comercio, reparación de autos, y enseres domésticos; y de industria manufacturera; pero mayor que el grupo de empresas de comercio, transporte y telecomunicaciones. Sin embargo, la desviación estándar de los rasgos de cultura organizacional es más bien homogénea.

Ilustración 5. Rasgos de cultura organizacional en subsectores de inmobiliarias, empaques y alquileres ${ }^{11}$
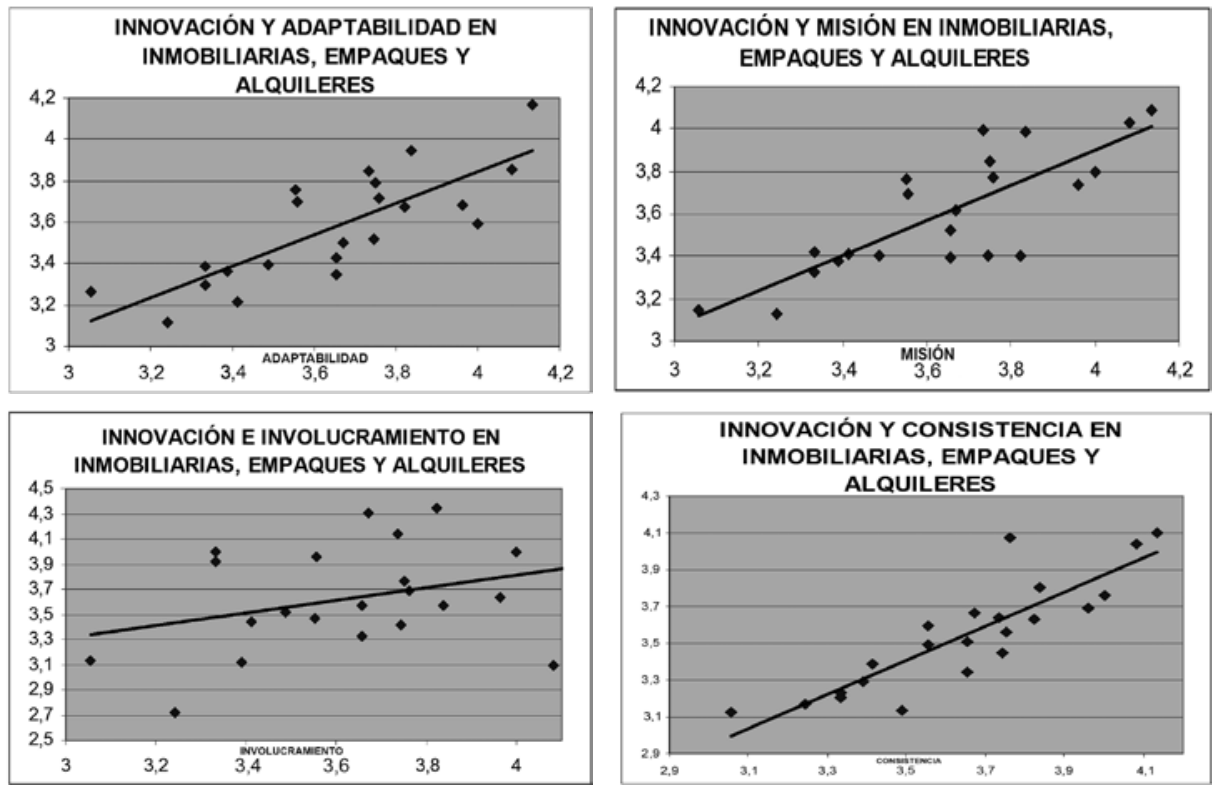

11 Fuente: Elaboración de los autores a partir de encuestas a empresas y cálculos propios. 
Las diferencias en los puntajes de los rasgos de cultura organizacional entre las empresas más y menos innovadoras son menores a dos décimas, y en el puntaje de innovación la diferencia es de casi dos décimas. Esto muestra que en este grupo de empresas hay más homogeneidad y las líneas de tendencia describen mejor el sector (ver Tabla 6).

El análisis gráfico ha permitido establecer que los grupos de empresas considerados en esta investigación se encuentran relaciones directas entre los puntajes de cultura organizacional e innovación. No obstante, como puede corroborarse en la Tabla 2, si bien no parece haber diferencias significativas de los perfiles de cultura organizacional de las cuatro agrupaciones de empresas, sí se encuentran diferencias especialmente al comparar a las firmas más y menos innovadoras de la agrupación de empresas de transporte, almacenamiento y comunicaciones, al compararla con las demás.

\subsection{Examen de asociación entre los ítems de cultura organizacional e innovación}

A cada una de las preguntas que examinan la cultura organizacional en la encuesta utilizada (DOCS) se le denomina un ítem en el modelo. Cinco ítems determinan un índice y tres índices a cada uno de los rasgos o características de cultura organizacional. En los siguientes acápites del artículo se pasa de los análisis gráfico y descriptivos a realizar análisis con herramientas estadísticas para los ítems, los índices y los rasgos o características de cultura organizacional.

Por medio del coeficiente gamma se estudia el grado de asociación entre la innovación y los ítems que señalan aspectos específicos de actitudes de quienes trabajan en las firmas y que definen a la cultura organizacional. En la Tabla 7 se muestran los mayores valores del coeficiente gamma para ítems de cada uno de los rasgos o características. Siendo quince los ítems por cada rasgo, se seleccionaron aquellos que mostraron mayores coeficientes y por tanto mayor asociación estadística con la innovación.

Debe tenerse en cuenta que valores menores a 0,15 en el coeficiente gamma muestran bajo grado de asociación entre las variables estudiadas y valores mayores a 0,3, alto grado de asociación. La gran mayoría de los coeficientes gamma estimados que fueron seleccionados en el Tabla y se encuentran entre 0,15 y 0,3 , asunto que permiten afirmar que a nivel de ítems existe asociación media entre la innovación y la cultura organizacional.

En los cuatro sectores estudiados se observa en general que los mayores coeficientes se dan en las características de misión y adaptabilidad. A nivel de sectores cabe anotar que los menores coeficientes de asociación entre innovación y cultura organizacional

Tabla 6. Perfil de las empresas más y menos innovadoras en subsectores de inmobiliarias, empaques y alquileres ${ }^{12}$

\begin{tabular}{|l|c|c|c|}
\hline $\begin{array}{c}\text { INMOBILIARIAS } \\
\text { EMPAQUES; ALQUILERES }\end{array}$ & MÁS INNOVADORAS & MENOS INNOVADORAS & DESVIAC. ESTÁNDAR \\
\hline INNOVACION & 4,13 & 3,14 & 0,41 \\
\hline INVOLUCRAMIENTO & 3,69 & 3,53 & 0,28 \\
\hline CONSISTENCIA & 3,57 & 3,40 & 0,30 \\
\hline ADAPTABIILIDAD & 3,61 & 3,41 & 0,27 \\
\hline MISIÓN & 3,65 & 3,41 & 0,29 \\
\hline FLEXIBILIDAD & 3,65 & 3,47 & 0,26 \\
\hline ESTABILIDAD & 3,61 & 3,41 & 0,28 \\
\hline FOCO EXTERNO & 3,63 & 3,41 & 0,27 \\
\hline FOCO INTERNO & 3,63 & 3,46 & 0,28 \\
\hline
\end{tabular}

12 Fuente: Elaboración de los autores a partir de encuestas a empresas y cálculos propios. 
se encontraron en las actividades inmobiliarias, de almacenamiento y empresariales. Los coeficientes gamma estimados fueron positivos. De manera que se demuestra una relación directa entre los puntajes de los ítems de cultura organizacional y la innovación (ver Tabla 7).

El mismo ítem en los diferentes sectores muestra diferentes niveles de asociación con la innovación. Es el caso de alta asociación entre innovación y la respuesta a la competencia (del rasgo adaptabilidad) que se tiene en la industria manufacturera; con el sector de comercio, vehículos y enseres, frente a los otros dos sectores, cuya asociación es media.

En los últimos renglones, se observa la asociación entre diversas formas de medición del desempeño y la innovación. Con solo una excepción en el sector de actividades inmobiliarias, de almacenamiento y comunicaciones, se observa que la innovación tiene alto grado de asociación con las otras formas de evaluar el desempeño de las firmas.

Tabla. 7. Coeficientes gamma entre innovación e ítems para los rasgos de cultura organizacional por sectores ${ }^{13}$

\begin{tabular}{|c|c|c|c|c|c|}
\hline & & $\begin{array}{c}\text { Industria } \\
\text { manufacturera }\end{array}$ & $\begin{array}{l}\text { Comercio, } \\
\text { vehiculos y } \\
\text { enseres }\end{array}$ & $\begin{array}{c}\text { Transporte, } \\
\text { almacenamiento y } \\
\text { comunicaciones }\end{array}$ & $\begin{array}{l}\text { Actividades } \\
\text { inmobiliarias, de } \\
\text { almacenamiento y } \\
\text { empresariales }\end{array}$ \\
\hline RASGO & & GAMMA & GAMMA & GAMMA & GAMMA \\
\hline INVOLUCRAMIENTO & $\begin{array}{l}\text { 5. La planificación empresarial es un proce- } \\
\text { so continuo que involucra a todos en cierto } \\
\text { grado. }\end{array}$ & 0,212 & 0,196 & 0,236 & 0,150 \\
\hline INVOLUCRAMIENTO & $\begin{array}{l}\text { 13. La empresa invierte continuamente para } \\
\text { mejorar las destrezas de los empleados. }\end{array}$ & 0,209 & 0,217 & 0,244 & 0,168 \\
\hline CONSISTENCIA & $\begin{array}{l}\text { 27. Las personas que están en diferentes } \\
\text { partes de la organización comparten una } \\
\text { perspectiva común. }\end{array}$ & 0,254 & 0,239 & 0,181 & 0,235 \\
\hline CONSISTENCIA & $\begin{array}{l}\text { 28. Es fácil coordinar proyectos entre las } \\
\text { diferentes partes de la organización. }\end{array}$ & 0,208 & 0,263 & 0,184 & 0,230 \\
\hline CONSISTENCIA & $\begin{array}{l}\text { 30. Las metas están alineadas en todos los } \\
\text { niveles. }\end{array}$ & 0,200 & 0,250 & 0,226 & 0,187 \\
\hline ADAPTABILIDAD & $\begin{array}{l}\text { 32. Respondemos bien a la competencia y a } \\
\text { otros cambios en el entorno comercial. }\end{array}$ & 0,303 & 0,353 & 0,268 & 0,207 \\
\hline ADAPTABILIDAD & $\begin{array}{l}\text { 42. Se alienta y recompensa el innovar y } \\
\text { tomar riesgos. }\end{array}$ & 0,173 & 0,218 & 0,278 & 0,195 \\
\hline MISIÓN & 49. Existe una clara estrategia para el futuro. & 0,238 & 0,319 & 0,278 & 0,209 \\
\hline MISIÓN & $\begin{array}{l}\text { 54. Seguimos continuamente nuestro pro- } \\
\text { greso en relación a las metas que hemos } \\
\text { establecido. }\end{array}$ & 0,280 & 0,337 & 0,205 & 0,202 \\
\hline MISIÓN & $\begin{array}{l}\text { 59. Nuestra visión estimula y motiva a nues- } \\
\text { tros empleados. }\end{array}$ & 0,315 & 0,260 & 0,281 & 0,183 \\
\hline DESEMPEÑO & 61. Crecimiento en ventas e ingresos & 0,509 & 0,393 & 0,304 & 0,279 \\
\hline DESEMPEÑO & 62. Porcentaje de mercado & 0,500 & 0,480 & 0,434 & 0,395 \\
\hline DESEMPEÑO & 63. Rentabilidad y rendimiento del activo & 0,476 & 0,452 & 0,416 & 0,355 \\
\hline DESEMPEÑO & 64. Calidad de productos y servicios & 0,557 & 0,538 & 0,517 & 0,369 \\
\hline DESEMPEÑO & 66. Satisfacción de los empleados & 0,384 & 0,461 & 0,368 & 0,352 \\
\hline DESEMPEÑO & 67. Rendimiento general de la empresa & 0,521 & 0,557 & 0,421 & 0,370 \\
\hline
\end{tabular}

13 Fuente: Elaboración de los autores a partir de encuestas a empresas y cálculos propios. 


\subsection{Examen de coeficientes de correlación y ras- gos de cultura organizacional por sectores}

Para examinar las asociaciones estadísticas entre las variables de cultura organizacional e innovación en las empresas, se procedió a estimar los coeficientes de correlación observándose que las asociaciones por sectores si encuentran diferencias, no obstante las similitudes que existen en general para los perfiles de cultura organizacional de los sectores.

Coherentemente con los gráficos presentados en secciones anteriores del documento, en la Tabla 7 se observan coeficientes de correlación positivos, lo cual demuestra que la relación entre las valoracio- nes de las variables de cultura organizacional y la innovación es directa. Definitivamente los valores y signos de los coeficientes de correlación permiten confirmar la asociación entre cultura organizacional $e$ innovación. Esta investigación es consistente con el trabajo previo de los autores en el cual se encontraron características culturales de las organizaciones que explican el desempeño de las firmas (Gómez \& Ricardo, 2009). Ampliándose ahora el número de empresas se pudo establecer que si bien los perfiles no cambian significativamente entre los sectores productivos considerados en la investigación, si hay diferencias entre los grados de asociación entre los rasgos de cultura organizacional y la innovación entre los diferentes sectores estudiados.

Tabla 7. Correlación entre innovación y cultura organizacional ${ }^{14}$

\begin{tabular}{|l|c|c|c|c|}
\hline & $\begin{array}{c}\text { INDUSTRIA } \\
\text { MANUFACTURERA }\end{array}$ & $\begin{array}{c}\text { COMERCIO. REPARACIÓN } \\
\text { DE AUTOS, ENSERES } \\
\text { DOMÉSTICOS }\end{array}$ & $\begin{array}{c}\text { TRANSPORTE, } \\
\text { ALMACENAMIENTO } \\
\text { COMUNICACIONES }\end{array}$ & $\begin{array}{c}\text { INMOBILIARIAS } \\
\text { EMPAQUES; ALQUILERES }\end{array}$ \\
\hline EMPODERAMIENTO & 0,49 & 0,421 & 0,76 & 0,21 \\
\hline ORIENTACIÓN AL GRUPO & 0,53 & 0,357 & 0,58 & 0,33 \\
\hline DESARROLLO DE CAPACIDADES & 0,62 & 0,348 & 0,50 & 0,41 \\
\hline VALORES CENTRALES & 0,44 & 0,452 & 0,48 & 0,23 \\
\hline ACUERDO & 0,43 & 0,304 & 0,35 & 0,27 \\
\hline COORDINACIÓN & 0,43 & 0,361 & 0,45 & 0,40 \\
\hline CREACIÓN DE CAMBIO & 0,54 & 0,466 & 0,49 & 0,17 \\
\hline FOCO EN EL CLIENTE & 0,38 & 0,400 & 0,39 & 0,38 \\
\hline APRENDIZAJE & 0,36 & 0,448 & 0,67 & 0,34 \\
\hline DIRECCIÓN ESTRATÉGICA & 0,43 & 0,560 & 0,75 & 0,33 \\
\hline OBJETIVOS Y METAS & 0,47 & 0,483 & 0,63 & 0,31 \\
\hline VISIÓN & 0,51 & 0,420 & 0,49 & 0,35 \\
\hline INVOLUCRAMIENTO & 0,58 & 0,395 & 0,69 & 0,29 \\
\hline CONSISTENCIA & 0,46 & 0,398 & 0,45 & 0,40 \\
\hline ADAPTABILIDAD & 0,43 & 0,522 & 0,70 & 0,35 \\
\hline MISION & 0,47 & 0,553 & 0,66 & 0,39 \\
\hline FLEXIBILIDAD & 0,53 & 0,466 & 0,71 & 0,33 \\
\hline ESTABILIDAD & 0,47 & 0,489 & 0,59 & 0,38 \\
\hline FOCO EXTERNO & 0,46 & 0,543 & 0,70 & 0,33 \\
\hline FOCO INTERNO & 0,53 & 0,403 & 0,59 & \\
\hline
\end{tabular}

14 Fuente: Elaboración de los autores a partir de encuestas a empresas y cálculos propios. 
El sector que muestra las más fuertes asociaciones (evaluado con los mayores coeficientes de correlación) entre las variables de cultura organizacional y la innovación es transporte, almacenamiento y comunicaciones. En éste las relaciones son más fuertes en los sesgos de flexibilidad y sesgo externo. El empoderamiento junto con la dirección estratégica se destacan por ser los índices con mayor asociación. A nivel de los sesgos se destacan la flexibilidad y el foco externo.

En la industria manufacturera los índices que más explican la innovación son el desarrollo de capacidades y la orientación al cambio sin dejar atrás la visión. Los sesgos que muestran mayor asociación son flexibilidad y foco interno. A nivel de características las asociaciones más fuertes son involucramiento y misión.

En el sector Comercio, reparación de automotores y enseres domésticos, los índices más relacionados con la innovación son dirección estratégica, objetivos y metas, así como valores centrales. Adaptabilidad y misión son las características con relaciones más fuertes, mientras que los sesgos de estabilidad y foco externo las mantienen con la innovación.

En términos generales, al considerar los cuatro sectores con los coeficientes de correlación, la característica de cultura organizacional que se muestra con menor asociación con la innovación es la consistencia. Sin embargo, ello no significa que su asociación estadística y funcional no sea importante para explicarla.

Siendo propósito de este trabajo examinar las relaciones del desempeño innovador con las variables de cultura organizacional, no queda duda que sus componentes son relevantes para explicarla. Cabe señalar que una matriz de correlaciones entre los diferentes componentes de cultura organizacional establece que las características tienen correlaciones que indican las relaciones internas entre ellas. No son variables estadísticamente independientes. Y si bien eso genera dificultades para analizar el fenómeno es claro que esto se explica por la extraordinaria complejidad de las ciencias sociales, que distan en sus métodos y en su tipo de conclusiones de las ciencias naturales.

\subsection{Análisis de consistencia o fiabilidad}

La confiabilidad y la validez son dos características que debe tener la información que se utiliza en la investigación. La validez se vincula con la exactitud y fidelidad con la realidad, mientras que la confiabilidad hace referencia a que los instrumentos utilizados siendo estables en el tiempo midan lo que deben. La información debe cumplir las dos características. En esta investigación se usa el alpha de Cronbach para examinar consistencia (que la medida esté libre de errores).

El alpha de Cronbach es un coeficiente de correlación elevado al cuadrado que mide la homogeneidad de las variables promediando las correlaciones entre los ítems (de carácter discreto como los utilizados en la estructura semántica de likert) para comprobar si se parecen. Si el coeficiente alpha de Cronbach es cercano a uno o menos uno, mayor es la fiabilidad de la información. Indica una relación cercana entre las variables, mientras que valores alrededor de cero apuntan a la inexistencia de relación. La confiabilidad o consistencia es el grado en que la aplicación repetida del instrumento al mismo sujeto u objeto, produce iguales resultados.

Cuando se tiene un valor del alfa de Cronbach cercano a uno o uno negativo, los ítems guardan buena correlación entre ellos pudiéndose concluir que la escala tiene un constructo válido. Por el contrario, si la correlación entre los ítems es pobre, se puede interpretar de tres maneras: i) que la escala no mide el constructo que se quiere medir; ii) que la conceptualización teórica del constructo es incorrecta; y iii) que el diseño experimental es inadecuado (Cronbach, citado por Oviedo \& Campo, 2005).

Un valor aceptable para el alpha de Cronbach es 0,7 . Debajo de este valor la consistencia interna es baja. El mayor valor esperado es 0,90 , porque al tener mayores valores se puede considerar que hay redundancia (varios ítems estarían midiendo el mismo elemento de un constructo). Este coeficiente es más fidedigno cuando se usa para veinte ítems o menos. También debe tenerse en cuenta que dicho coeficiente tiende a aumentar cuando el número de variables aumenta (Streiner, citado por Oviedo \& Campo, 2005). 
El alfa de Cronbach se define como:

$\alpha=\frac{K}{K-1}\left[1-\frac{\sum S_{i^{2}}}{S_{T^{2}}}\right]$

Donde:

$K$ : El número de ítems

Si2: Sumatoria de Varianzas de los ítems

ST2: Varianza de la suma de los ítems

$\alpha$ : Coeficiente de Alpha de Cronbach

El modelo de Denison agrupa quince ítems (cada uno definido con variables ordinales de uno a cinco) para formar cada una de las cuatro características o rasgos de cultura organizacional. En esta investigación se examinan las agrupaciones de ítems que conforman las características o rasgos de cultura organizacional de las empresas que participaron en ella mediante el alpha de Cronbach validando la información que se ha presentado hasta el momento y antes de proceder a la estimación del modelo logit ordenado con el cual se toman simultáneamente las características de cultura organizacional como variables explicativas de la innovación.

En la Tabla 8 se presentan los resultados de los ítems que conforman cada una de las características y se verifica su consistencia o fiabilidad interna. Los resultados obtenidos permiten confirmar la fiabilidad de la información y un grado de asociación conjunto de las variables que conforma cada característica con la variable de la innovación utilizada en la investigación.
Reconfirmadas las bondades de la información de los coeficientes de correlación por medio del coeficiente alpha de Cronbach, se sientan bases para hacer las contrastaciones del modelo logit ordenado con el cual se evalúa la cultura organizacional como determinante de la innovación en las empresas bogotanas.

\subsection{Modelo logit ordenado: innovación y rasgos o características de cultura organizacional}

Como variable explicativa de la regresión logit ordenada se utilizó al ítem sesenta y cinco y como variables explicativas a involucramiento (invol), consistencia (consi), adaptabilidad (adapta) y misión. El ítem sesenta y dos representa una variable categórica cuyos valores enteros de uno a cinco representan la creciente participación en el mercado. Las variables que representan a los sectores de industria manufacturera (dind) y comercio, reparación de autos y enseres domésticos (dcio) son variables binarias que identifican a las empresas de los respectivos subsectores.

El modelo logit ordenado reconfirma con los signos esperados y significancia estadística la asociación entre las características de cultura organizacional $e$ innovación (ver Tabla 9). Del modelo se puede afirmar que quienes tienen mayor puntaje en el rasgo de adaptabilidad tienen 1,59 veces mayor probabilidad de innovar. Así mismo quienes tienen mayores puntajes en el rasgo involucramiento tienen 1,21 veces más probabilidad de innovar que aquellos que tienen menor puntaje. Estos resultados son coherentes con lo esperado con la teoría.

Tabla 8. Alpha de Cronbach para rasgos de cultura organizacional e innovación ${ }^{15}$

\begin{tabular}{|l|c|}
\hline \multicolumn{1}{|c|}{ Rasgo o característica } & $\begin{array}{c}\text { Alpha de } \\
\text { Cronbach }\end{array}$ \\
\hline Involucramiento (ítems uno a quince) e innovación-ítem sesenta y cinco) & 0,84 \\
\hline Consistencia (ítems diez y seis a treinta e innovación-ítem sesenta y cinco) & 0,80 \\
\hline Adaptabilidad (ítems treinta y uno a cuarenta y cinco e innovación-ítem sesenta y cinco) & 0,74 \\
\hline Misión (ítems cuarenta y seis a sesenta e innovación-ítem sesenta y cinco) & 0,83 \\
\hline
\end{tabular}

15 Fuente: Elaboración de los autores a partir de encuestas a empresas y cálculos propios. 
Tabla 9. Modelo logit: rasgos de cultura organizacional, sectores y mercado ${ }^{19}$

\begin{tabular}{|l|c|c|}
\hline \multicolumn{1}{|c|}{ Variable } & coeficiente & Odd ratio \\
\hline Involucramiento & 0,1940 & $\begin{array}{c}1,21^{*} \\
(0.0682)\end{array}$ \\
\hline Consistencia & 0,1211 & $\begin{array}{c}1.12^{* *} \\
(0,0712)\end{array}$ \\
\hline Adaptabilidad & 0,4621 & $\begin{array}{c}1,59^{*} \\
(0,1367)\end{array}$ \\
\hline Misión & 0,1578 & $\begin{array}{c}1,17^{* *} \\
(0.0986)\end{array}$ \\
\hline $\begin{array}{l}\text { Dummy del sector } \\
\text { industrial }\end{array}$ & 0,1222 & $\begin{array}{c}1,13^{*} \\
(1,1299)\end{array}$ \\
\hline $\begin{array}{l}\text { Dummy del sector } \\
\text { comercio }\end{array}$ & 0,2824 & $\begin{array}{c}1,33^{*} \\
(0,0719)\end{array}$ \\
\hline $\begin{array}{l}\text { Prticipación en el } \\
\text { mercado-P62 }\end{array}$ & 0,7405 & $\begin{array}{c}2,09 * \\
(0.0595)\end{array}$ \\
\hline $\begin{array}{l}\text { Log pseudo likelihood } \\
11644,42\end{array}$ & Wald Chi $2(7)$ & \\
\hline No. de observaciones & 9497 & \\
\hline AIC & 23310 & \\
\hline
\end{tabular}

No obstante los mayores puntajes de los perfiles en misión, el modelo señala (con significancia del 10\%) que quienes tienen mayores puntajes en misión tienen 1,17 veces más probabilidad de innovar que quienes tienen un puntaje menor. Quienes tienen puntajes mayores en consistencia (con significancia del $10 \%$ ) tienen probabilidad 1,12 veces mayor.

Las variables sectoriales que muestran relación con la innovación son las variables dummy de los sectores comercio e industria manufacturera. El mayor coeficiente corresponde a la participación en el mercado. El modelo logit ordenado que se utilizó en esta investigación también revela el grado de asociación entre las características de cultura organizacional $e$ innovación, pero además reconoce la capacidad explicativa de los diferentes sectores y de la participación en el mercado.

\section{Conclusiones}

El análisis de datos y el Denison Organisational Culture Survey (DOCS) mostró sus virtudes para estudiar los perfiles culturales de las empresas bogotanas pertenecientes a cuatro sectores productivos. Los perfiles de cultura organizacional de los diversos sectores son bastante parecidos. Los coeficientes gama y los coeficientes de correlación entre innovación y las variables de cultura organizacional de los sectores son diferentes, no obstante lo parecido de los puntajes de los perfiles de cultura organizacional. La relación entre las variables de cultura organizacional vistas en los coeficientes de correlación dificultan la aplicación de modelos econométricos como la regresión lineal múltiple para explicar la innovación, pues usualmente se requiere independencia entre las variables explicativas.

Si bien en todos los sectores se aprecia la existencia de relaciones estadísticas entre la innovación y las variables de cultura organizacional, los mayores coeficientes de correlación se observaron en el sector de transporte, almacenamiento y comunicaciones y luego el sector de industria manufacturera. Sin dejar de tener asociación estadística significativa entre la innovación y los índices, sesgos y características, el sector con menores coeficientes de correlación fue inmobiliarias, empaques y alquileres.

A nivel de ítems los mayores coeficientes gamma y por tanto asociación media entre innovación y cultura se presentaron en el sector comercio, vehículos $y$ enseres y los menores en inmobiliarias empaques y alquileres. En su orden el mejor desempeño innovador de los sectores se dio en: comercio, reparación de automotores y enseres domésticos; segundo, en industria manufacturera; tercero, en transporte, almacenamiento y comunicaciones; y cuarto, en inmobiliarias, empaques y alquileres.

Los índices examinados con coeficientes de correlación, que presentaron mayor asociación estadística

16 Fuente: Elaboración de los autores a partir de encuestas a empresas y cálculos propios. Errores estándar robustos entre paréntesis, así:

* Significativos al 5\%

** Significativos al 10\%.

Variable dependiente: innovación (ítem65) 
con la innovación fueron empoderamiento, dirección estratégica, objetivos y metas, y aprendizaje. A nivel de sesgos las mayores relaciones se observaron en flexibilidad y foco externo. En las características, las mayores asociaciones se dieron en involucramiento y misión. Es de observarse que los índices tuvieron coeficientes de correlación más altos que los sesgos y estos que las características. De manera que si bien hay unos índices que muestran una mayor relación estadística con la innovación, ésta sólo puede llevarse a cabo con contribuciones oportunas y adecuadas de otros aspectos de la cultura organizacional.

Si bien el involucramiento y adaptabilidad son importantes para estimular la creatividad, misión y consistencia son imprescindibles para la ejecución y la implementación que resultan en la innovación en las organizaciones. Las firmas que sean más capaces de desarrollar y balancear las cuatro características de sus culturas serán las más proclives a continuar innovando y mantenerse competitivas. O sea, que en términos gerenciales, el desarrollo de la cultura organizacional en las cuatro características puede significar a futuro un mejor desempeño innovador, $y$ por lo tanto mayores niveles de competitividad.

Las empresas de los diferentes sectores ordenadas por los cuartiles de mayor y menor innovación al ser comparados sus perfiles de cultura organizacional, muestran que existen diferencias entre dos y tres décimas en sus respectivos puntajes de los rasgos. Las mayores diferencias están en los promedios mismos de innovación cuyas diferencias están entre diez y doce décimas. Los menores puntajes se dieron en el sector de transporte, almacenamiento y comunicaciones.

El alto nivel de asociación visto en los coeficientes gamma para la innovación frente a las otras medidas de desempeño confirma el carácter estratégico de la innovación para las empresas. La gestión de la cultura organizacional orientada hacia los procesos de cambio organizacional y la innovación impacta a las otras formas de desempeño de las firmas.

El alpha de Cronbach permitió confirmar la consistencia de la información de cultura organizacional utilizada en la investigación. El modelo logit ordena- do reconfirma la asociación y explicación de la innovación con los rasgos de cultura organizacional. Estos rasgos que tienen mayor probabilidad de impactar la innovación son, consistentemente con la teoría: adaptabilidad $e$ involucramiento. No obstante que los rasgos con mayor puntaje fueron los de misión, aquellas empresas que tiene mayores puntajes en este rasgo organizacional, tienen apenas una probabilidad 1,17 veces mayor que las que tienen menor puntaje. Así mismo las que tienen en consistencia mayor puntaje tienen una probabilidad 1,12 veces mayor de innovar, que las demás con menor puntaje.

De los resultados del modelo logit ordenado se concluye que las empresas con mayor puntaje en el rasgo de adaptabilidad tienen 1,59 veces mayor probabilidad de innovar. Así mismo, quienes tienen mayores puntajes en el rasgo involucramiento tienen 1,21 veces más probabilidad de innovar que aquellos que tienen menor puntaje. Estos resultados son coherentes con lo señalado por la teoría.

\section{Referencias}

Baker, K. (2004). Organisational culture. Chapter 11. Disponible en: http:// www.maxwell.af.mil/au/awc/awcgate/doe/benchmark/ch11.pdf

Becker, G. (1964). Human capital: A theoretical and empirical analysis with special reference to education. New York. Columbia University Press.

Block, P. (1991). The empowered manager: Positive political skills at work. San Francisco. Jossey Bass.

Boyce, A. (2010). Organizational climate and performance: An examination of causal priority. Doctoral dissertation, Michigan State University.

Davenport, T. (1993). Process innovation: Re-engineering work through information technology. Boston. Harvard Business School Press.

Denison, D. (1982). The climate, culture, and effectiveness of work organizations: A study of organizational behavior and financial performance. Doctoral dissertation, University of Michigan.

Denison, D. (1984). Bringing corporate culture to the bottom line. En: Organizational Dynamics, 13: 4-22.

Denison, D. (1990). Corporate Culture and Organizational Effectiveness. New York: Wiley.

Denison, D. (2000) Organisational Culture: Can it be a key lever for driving organisational change? International Institute for Management Development, June.

Denison, D., Haaland, S. \& Goelzer, P. (2003a). Corporate culture and organizational effectiveness: Is Asia different From the rest of the world? En: Organizational Dynamics, 33 (1): 98-109.

Denison, D., Haaland, S. \& Goelzer, P. (2003b). Corporate culture and organizational effectiveness: Is there a similar pattern around the world? En: Advances in Global Leadership, 3: 205-227. 
Denison, D., Hooijberg, R., Lane, N. \& Lief, C. (2012). Leading Culture Change in Global Organizations. San Francisco: JosseyBass/Wiley.

Denison, D. \& Mishra, A. (1995). Toward a theory of organisational culture and effectiveness. En: Organisation Science, 6(2): 204-223.

Denison, D. \& Neale, W. (1996). Denison organisational culture survey. Facilitator guide. Denison Consulting. Ann Arbor. Michigan.

Denison Consulting (2008). Research Notes. Vol. 2. Disponible en: http://www.denisonconsulting.com/Libraries/Resources/ RN Organizational Culture and Innovation 200812.sflb.ashx

Fey, C. \& Denison, D. (2003). Organisational Culture and Effectiveness: Can American Theory Be Applied in Russia? Working Paper 598. Disponible en: http://wdi.umich.edu/files/publications/ workingpapers/wp598.pdf

Flynn, F. \& Chatman, J. (2001). Strong Cultures and Innovation: Oxymoron or Opportunity? En: Cooper, C. \& Cartwright, S. \& Earley, P. (Eds.) International Handbook of Organizational Culture and Climate: 263-287. West Sussex, UK: John Wiley \& Sons Limited.

Gisbert, M. (2005). Creatividad e Innovación en la Práctica Empresarial. Madrid. Fundación Cotec para la Innovación Tecnológica. Colección Estudios.

Gómez, I. \& Ricardo, R. (2009) Similarities and diferences existing in cultural profiles of colombian organizartions of higher and lower performance. En: Revista Facultad de Ciencias Económicas: Investigación y Refexión, Universidad Militar Nueva Granada, Vol. XVII (1).

Gregory, B., Harris, S., Armenakis, A. \& Shook, C. (2009). Organizational culture and effectiveness: A study of values, attitudes, and organizational outcomes. En: Journal of Business Research, 62 .

Hamel, G. \& Prahalad, C. (1994). Competing for the future. Boston. Harvard Business School Press. Disponible en: http://www. hsfulda.de/fileadmin/Fachbereich SW/Downloads/Profs/Wolf/ Studies/colombian/colombian.pdf

Lawler, E. (1996). From the ground up: Six principles for building the new logic corporation. San Francisco. Jossey Bass.

Likert, R. (1961). New patterns of management. New York. McGraw Hill.

Linnenluecke, M. \& Griffiths, A. (2009) Corporate sustainability and organizational culture. En: Journal Of World Business, 45 (4): 357-366.
Martensen, A. \& Dahlgaard, J. (1999). Strategy and planning for innovation management-supported by creative and learning organizations. En: International Journal of Quality and Reliability Management, 16 (9): 878-891.

Mintzberg, H. (1987). Crafting strategy. En: Harvard Business Review, 65, 66-75.

Mobley, W., Wang, L. \& Fang, K. (2005). Organisational culture: measuring and developing it in your organisation. En: Harvard Business Review China, March: 6.

Morcillo, P. (2007). Cultura e innovación empresarial. España. Thomson.

Ogliastri, E. (1998). Culture and organizational leadership in Colombia. En: Organisation Science, 14 (6): 686-706.

Ohmae, K. (1982). The Mind of the Strategist. McGraw-Hill, New York.

Oviedo, H. \& Campo, A. (2005). Aproximación al uso del coeficiente alfa de Cronbach. En: Revista colombiana de psiquiatría, Asociación Colombiana de Psiquiatría, XXIV (4): 572-580.

Saffold, G. (1988). Culture traits, strength, and organisational performance: Moving beyond "strong" culture. En: Academy of Management Review, 13(4): 546-558.

Schein, E. (2010) Organizational Culture and Leadership (4th ed.). San Francisco: Jossey-Bass/Wiley.

Schein, E.H. (1985). Organisational culture and leadership. San Francisco. Jossey-Bass.

Schumpeter, J. (1942). Capitalismo Socialismo y Democracia. Buenos Aires, Editorial Claridad.

Senge, P. (1990). The fifth discipline: The art and practise of the learning organisation. New York. Doubleday/Currency.

Smerek, R. \& Denison, D. (2007). Social capital in organizations: Understanding the link to firm performance. Academy of $\mathrm{Ma}$ nagement Best Paper Proceedings.

Spreitzer, G. (1995). Psychological empowerment in the workplace: Dimensions, measurement, and validation. En: Academy of Management Journal, 38: 1442-1465.

Stalk, J. (1988). Competing against time: How time-based competition is reshaping global markets. New York. Free Press.

Vence, X. (2007). Crecimiento y políticas de innovación: nuevas tendencias y experiencias comparadas. España. Ediciones Pirámide.

West, M. \& Farr, J. (1990). Innovation and creativity at work: Psychological and organizational strategies. Chichester: Wiley. 


\section{Anexo 1}

Resultados modelo logit ordenado: innovación y cultura organizacional ${ }^{17}$

- ologit p65 invol consi adapta mision dind dcio p62, vce(robust) or

$\begin{array}{lll}\text { Iteration 0: } & \text { log pseudolikelihood }=-12538.039 \\ \text { Iteration 1: } & \text { log pseudolikelihood }=-11660.787 \\ \text { Iteration 2: } & \log \text { pseudolikelihood }=-11644.47 \\ \text { Iteration 3: } & \text { log pseudolikelihood }=-\mathbf{1 1 6 4 4 . 4 2 1} \\ \text { Iteration 4: } & \text { log pseudolikelihood }=-\mathbf{1 1 6 4 4 . 4 2 1}\end{array}$

Ordered logistic regression

Number of obs $=9497$

wald chi2(7) $=1480.34$

Prob $>$ chi2 $=0.0000$

Log pseudolikelihood $=-11644.421$

Pseudo R2

0.0713

\begin{tabular}{r|rccccr}
\hline p65 & Odds Ratio & $\begin{array}{c}\text { Robust } \\
\text { Std. Err. }\end{array}$ & $z$ & $P>|z|$ & [95\% Conf. Interval] \\
\hline invo1 & 1.214149 & .0682868 & 3.45 & 0.001 & 1.087422 & 1.355644 \\
consi & 1.128717 & .0712489 & 1.92 & 0.055 & .9973648 & 1.277368 \\
adapta & 1.587366 & .1366847 & 5.37 & 0.000 & 1.340856 & 1.879197 \\
mision & 1.17092 & .0985828 & 1.87 & 0.061 & .9928017 & 1.380995 \\
dind & 1.129935 & .0505846 & 2.73 & 0.006 & 1.035016 & 1.233559 \\
dcio & 1.326344 & .0718801 & 5.21 & 0.000 & 1.192686 & 1.474981 \\
p62 & 2.097063 & .0595158 & 26.09 & 0.000 & 1.983599 & 2.217017 \\
\hline /cut1 & 1.865882 & .1906086 & & & 1.492296 & 2.239469 \\
/cut2 & 3.69619 & .1790905 & & & 3.345179 & 4.047201 \\
/cut3 & 5.839791 & .1818948 & & & 5.483284 & 6.196298 \\
/cut4 & 7.885425 & .1896191 & & & 7.513779 & 8.257072 \\
\hline
\end{tabular}

- estat ic

\begin{tabular}{r|rrrrrr}
\hline Mode1 & Obs & 11 (nu11) & 11 (mode1) & df & AIC & BIC \\
\hline$\cdot$ & 9497 & -12538.04 & -11644.42 & 11 & 23310.84 & 23389.59 \\
\hline
\end{tabular}

Note: $N$ Obs used in calculating BIC; see [R] BIC note

- Tinktest

$\begin{array}{ll}\text { Iteration 0: } & \text { log likelihood }=-12538.039 \\ \text { Iteration 1: } & \text { log likelihood }=-11659.946 \\ \text { Iteration 2: } & \text { log likelihood }=-11643.151 \\ \text { Iteration 3: } & \text { log likelihood }=-11643.102 \\ \text { Iteration 4: } & \text { log likelihood }=-11643.102\end{array}$

ordered logistic regression

Number of obs = 9497 LR $\operatorname{chi2}(2)=1789.87$ Prob $>$ chit $=0.0000$

Log Tikelihood $=-11643.102$

Pseudo R2 $=0.0714$

\begin{tabular}{|c|c|c|c|c|c|c|}
\hline p65 & Coef. & Std. Err. & $z$ & $P>|z|$ & [95\% Conf. & Interval] \\
\hline hat & .6476453 & .2182753 & 2.97 & 0.003 & .2198336 & 1. 075457 \\
\hline hatsq & .0293111 & .0180493 & 1.62 & 0.104 & -.0060649 & .064687 \\
\hline $\begin{array}{l}\text { /cut1 } \\
\text { /cut2 }\end{array}$ & $\begin{array}{l}.8414098 \\
2.662295\end{array}$ & $\begin{array}{l}.6498187 \\
.6527128\end{array}$ & & & $\begin{array}{r}-.4322115 \\
1.383001\end{array}$ & $\begin{array}{l}2.115031 \\
3.941588\end{array}$ \\
\hline /cut3 & 4.799545 & .6577281 & & & 3.510422 & 6.088668 \\
\hline /cut4 & 6.850531 & .6566627 & & & 5.563496 & 8.137566 \\
\hline
\end{tabular}

16 Fuente: Elaboración propia a partir de datos de la investigación. 